\title{
RECIL PD
}

National Cancer Institute

\section{Source}

National Cancer Institute. RECIL PD. NCI Thesaurus. Code C159622.

Greater than 20 percent increase in the sum of longest diameters of target lesions; For small lymph nodes measuring less than $15 \mathrm{~mm}$ post therapy, a minimum absolute increase of $5 \mathrm{~mm}$ and the long diameter should exceed $15 \mathrm{~mm}$; Appearance of a new lesion. 